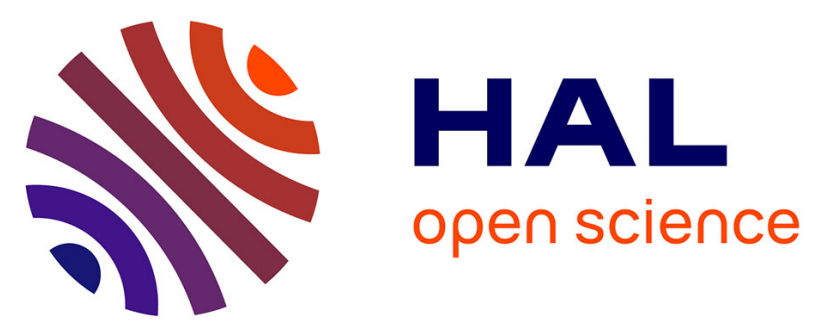

\title{
Comparative Analysis of Estimation Techniques of SFOC Induction Motor for Electric Vehicles
}

\author{
Abdelhakim Haddoun, Mohamed Benbouzid, Demba Diallo, Rachid
}

Abdessemed, Jamel Ghouili, Kamel Srairi

\section{- To cite this version:}

Abdelhakim Haddoun, Mohamed Benbouzid, Demba Diallo, Rachid Abdessemed, Jamel Ghouili, et al. Comparative Analysis of Estimation Techniques of SFOC Induction Motor for Electric Vehicles. ICEM'08, Sep 2008, Vilamoura, Portugal. pp.ID 1436. hal-00531296

\section{HAL Id: hal-00531296 \\ https://hal.science/hal-00531296}

Submitted on 3 Nov 2010

HAL is a multi-disciplinary open access archive for the deposit and dissemination of scientific research documents, whether they are published or not. The documents may come from teaching and research institutions in France or abroad, or from public or private research centers.
L'archive ouverte pluridisciplinaire HAL, est destinée au dépôt et à la diffusion de documents scientifiques de niveau recherche, publiés ou non, émanant des établissements d'enseignement et de recherche français ou étrangers, des laboratoires publics ou privés. 


\title{
Comparative Analysis of Estimation Techniques of SFOC Induction Motor for Electric Vehicles
}

\author{
A. Haddoun ${ }^{1,2}$, M.E.H. Benbouzid ${ }^{1}$, D. Diallo ${ }^{3}$, R. Abdessemed ${ }^{4}$, J. Ghouili ${ }^{5}$ and K. Srairi ${ }^{6}$ \\ ${ }^{1}$ Laboratoire Brestois de Mécanique et des Systèmes (LBMS - EA 4325), University of Brest \\ IUT of Brest - Rue de Kergoat - CS 93837, 29238 Brest Cedex 03, France, E-mail: m.benbouzid@ieee.org \\ ${ }^{2}$ Electrical Engineering Department, University of Oum El Bouaghi, 04000 Oum El Bouaghi, Algeria \\ ${ }^{3}$ LGEP/SPEE labs, CNRS UMR 8507, Supélec; Univ. Pierre et Marie Curie P6; Univ. Paris Sud P11, 91192 Gif-Sur-Yvette, France \\ ${ }^{4}$ Electrical Engineering Department, University of Batna, Batna, Algeria \\ ${ }^{5}$ GRET Research Group, Engineering Faculty, University of Moncton, Moncton, New Brunswick, Canada \\ ${ }^{6}$ Laboratoire de Modélisation des Systèmes Energétiques (LMSE), University of Biskra, 07000 Biskra, Algeria
}

\begin{abstract}
This paper presents system analysis, modeling and simulation of an electric vehicle with different sensorless control techniques. Indeed, sensorless control is considered to be a lower cost alternative than the position or speed encoder-based control of induction motors for an electric vehicle. Two popular sensorless control methods, namely, the Luenberger observer and the Kalman filter methods are compared regarding speed and torque control characteristics. They are also compared against the well-known model reference adaptive system. Simulations on a test vehicle propelled by $37-\mathrm{kW}$ induction motor lead to very interesting comparison results.
\end{abstract}

Index Terms-Electric Vehicle (EV), induction motor, Model Reference Adaptive System (MRAS), Luenberger Observer (LO), Kalman Filter (KF), speed estimation, traction control.

\section{INTRODUCTION}

Field-Oriented Control (FOC) of induction motors is a prevailing design of electric drive for EVs. Drives Efficiency is crucial to saving energy and offering more range. Induction motors drives for EVs require the control strategy operating with efficiency maximization and high dynamic performance at varying speed and load.

Research and development on speed sensorless control of induction motor drives have continued over the past two decades [1-2]. The most effective sensorless control techniques mentioned in the literature are MRAS, the Luenberger and Kalman filter observers [3-6]. In MRAS, speed is estimated using the difference between the reference model output and the adjustable model output. One problem encountered in MRAS is the integration of pure voltage signals. One can solve this problem by modifying the pure integration in voltage model to the low-pass filter. However, one can insert a linear transfer function in the form of high-pass filter in both the reference and the adjustable models. Due to the presence of this low-pass filter, there is a natural delay related to the filter. In the literature some authors improved this method by proposing a robust flux observer of which the poles are designed in function of rotor speed and time constant [7-8].

This paper mainly concentrates on comparing the performance of the above cited three speeds sensorless control techniques applied for EVs propelled by an induction motor drive.

\section{VEHICLE MODEL}

The proposed control strategy takes into account the vehicle aerodynamics, and is not applied to the sole induction motors. The vehicle model is based on mechanics and aerodynamics principles [9-10]. The total tractive effort is then given by

$$
F_{t e}=F_{r r}+F_{a d}+F_{h c}+F_{l a}+F_{w a}
$$

Where $F_{r r}=$ is the rolling resistance force;

$F_{a d}=$ is the aerodynamic drag;

$F_{h c}=$ is the hill climbing force;

$F_{l a}=$ is the force required to give linear acceleration;

$F_{w a}=$ is the force required to give angular acceleration to the rotating motor.

It should be noted that $F_{l a}$ and $F_{w a}$ will be negative if the vehicle is slowing down and that $F_{h c}$ will be negative if it is going downhill. The power required to drive a vehicle at a speed $v$ has to compensate counteracting forces.

$P_{t e}=v F_{t e}=v\left(F_{r r}+F_{a d}+F_{h c}+F_{l a}+F_{w a}\right)$

\section{INDUCTION MOTOR MODELING}

\section{A. Nomenclature}

$\begin{array}{ll}V_{d s}\left(V_{q s}\right) & =d \text {-axis }(q \text {-axis) stator voltages; } \\ i_{d s}\left(i_{q s}\right) & =d \text {-axis } q \text {-axis) stator currents; } \\ \lambda_{d r}\left(\lambda_{q r}\right) & =d \text {-axis }(q \text {-axis) rotor flux linkages; } \\ T_{m}\left(T_{L}\right) & =\text { Mechanical (load) torque; } \\ R_{s}\left(R_{r}\right) & =\text { Stator (rotor) resistance; } \\ L_{s}\left(L_{r}\right) & =\text { Stator (rotor) inductance; } \\ L_{m} & =\text { Magnetizing inductance; } \\ L_{\sigma} & =\text { Leakage inductance }\left(L_{\sigma}=L_{s}-L_{m}{ }^{2} / L_{r}\right) ; \\ \omega_{e}\left(\omega_{r}\right) & =\text { Stator (rotor) electrical speed; } \\ \Omega & =\text { Rotor speed }\left(\omega_{r} / \mathrm{p}\right) ; \\ \omega_{s l} & =\text { Slip frequency, }\left(\omega_{s l}=\omega_{s}-\omega_{r}\right) ; \\ B & =\text { Motor damping ratio; } \\ p & =\text { Pole-pair number; } \\ T_{r} & =\text { Rotor circuit time constant }\left(T_{r}=L_{r} / R_{r}\right) .\end{array}$


Proceedings of the 2008 International Conference on Electrical Machines

$$
\left\{\begin{array}{l}
k_{1}=\frac{R_{s}}{L_{\sigma}}+\frac{R_{r} L_{m}^{2}}{L_{r}^{2} L_{\sigma}}, k_{2}=\frac{R_{r} L_{m}}{L_{r}^{2} L_{\sigma}}, k_{3}=\frac{L_{m}}{L_{r} L_{\sigma}}, \\
k_{4}=\frac{R_{r} L_{m}}{L_{r}}, k_{5}=\frac{R_{r}}{L_{r}}, k_{6}=\frac{1}{L_{\sigma}}, k_{t}=\frac{3}{2} p \frac{L_{m}}{L_{r}}
\end{array}\right.
$$

\section{B. Induction Motor Dynamic Model}

The induction motor dynamic model in the $d-q$ synchronously rotating frame with rotor flux is described by [9].

$$
\begin{aligned}
& \frac{d}{d t}\left[\begin{array}{c}
i_{d s} \\
i_{q s} \\
\lambda_{d r} \\
\lambda_{q r}
\end{array}\right]=\left[\begin{array}{cccc}
-k_{1} & \omega_{e} & k_{2} & \omega_{r} k_{3} \\
-\omega_{e}-k_{1} & -\omega_{r} k_{3} & k_{2} \\
k_{4} & 0 & -k_{5} & \omega_{s l} \\
0 & k_{4} & -\omega_{s l} & -k_{5}
\end{array}\right]\left[\begin{array}{c}
i_{d s} \\
i_{q s} \\
\lambda_{d r} \\
\lambda_{q r}
\end{array}\right]+k_{6}\left[\begin{array}{c}
V_{d s} \\
V_{q s} \\
0 \\
0
\end{array}\right] \\
& \frac{d \omega_{r}}{d t}=-\frac{B}{J} \omega_{r}-\frac{1}{J}\left(T_{m}-T_{L}\right) \\
& T_{m}=k_{t}\left(\lambda_{d r} i_{q s}-\lambda_{q r} i_{d s}\right)
\end{aligned}
$$

\section{The Model Reference AdAPTIVE System}

Adaptive control has emerged as a potential solution for implementing high-performance control systems, especially when dynamic characteristics of a plant are unknown, or have large and unpredictable variations. The MRAS achieves robust and high-performance because of the presence of a reference model which specifies the desired performance. The adaptation scheme uses stator voltages and currents, where the reference model output is compared to an adaptive model output. Then the rotor speed is estimated based on the difference between these state variables. A number of MRAS-based speed sensorless schemes have been described in the literature for field-oriented induction motor drives [3-4], [11-12].

The general block diagram for MRAS is shown in Fig.1. The stator voltage equation for $v_{d s}$ in the $d$-q equivalent circuit can be written as

$v_{d s}=R_{s} i_{d s}+L_{s} \frac{d i_{d s}}{d t}+\frac{d \lambda_{d m}}{d t}$

The $d$ component of rotor flux can be expressed as

$\lambda_{d r}=\frac{L_{r}}{\lambda_{m}} \lambda_{d m}-L_{r} i_{d s}$

and then $\lambda_{d m}=\frac{L_{m}}{L_{r}}\left(\lambda_{d r}+L_{r} i_{d s}\right)$

Subscripts $d$ and $q$ refers to the direct and the quadrature axis, respectively. Subscripts $s$ and $r$ refer to stator and rotor respectively, and $m$ refers to the magnetizing component.

Substituting $\lambda_{d m}$ in (6) gives



Fig. 1. MRAS block diagram.

$$
\begin{aligned}
& v_{d s}=\frac{L_{m}}{L_{r}} \frac{d \lambda_{d r}}{d t}+\left(R_{s}+\sigma L_{s} S\right) i_{d s} \\
& \text { and } \frac{d \lambda_{d r}}{d t}=\frac{L_{r}}{L_{m}} v_{d s}-\frac{L_{r}}{L_{m}}\left(R_{s}+\sigma L_{s} S\right) i_{d s}
\end{aligned}
$$

Similarly, $\lambda_{q r}$ can be expressed as

$\frac{d \lambda_{q r}}{d t}=\frac{L_{r}}{L_{m}} v_{q s}-\frac{L_{r}}{L_{m}}\left(R_{s}+\sigma L_{s} S\right) i_{q s}$

Equations (10) and (11) together make up the reference model or the voltage model. The model calculates the rotor fluxes from the motor stator voltage and current signals. The adjustable or adaptive model is constructed using the current flux model equations. The rotor circuit equations in the $d-q$ synchronously equivalent circuits may be written as

$\left\{\begin{array}{l}\frac{d \lambda_{d r}}{d t}+R_{r} i_{d r}+\omega_{r} \lambda_{q r}=0 \\ \frac{d \lambda_{q r}}{d t}+R_{r} i_{q r}-\omega_{r} \lambda_{d r}=0\end{array}\right.$

Adding $\left(L_{\mathrm{m}} R_{r} / L_{\mathrm{r}}\right) i_{d s}$ and $\left(L_{\mathrm{m}} R_{r} / L_{\mathrm{r}}\right) i_{q s}$ on both sides of (12) and substituting

$$
\left\{\begin{array}{l}
\lambda_{d r}=L_{m} i_{d s}+L_{r} i_{d r} \\
\lambda_{q r}=L_{m} i_{q s}+L_{r} i_{q r}
\end{array}\right.
$$

We have $\left\{\begin{array}{l}\frac{d \lambda_{d r}}{d t}=\frac{L_{m}}{T_{r}} i_{d s}-\omega_{r} \lambda_{q r}-\frac{1}{T_{r}} \lambda_{d r} \\ \frac{d \lambda_{q r}}{d t}=\frac{L_{m}}{T_{r}} i_{q s}+\omega_{r} \lambda_{d r}-\frac{1}{T_{r}} \lambda_{q r}\end{array}\right.$

Hence, the adaptive model may be represented as 
Proceedings of the 2008 International Conference on Electrical Machines

$$
\left[\begin{array}{l}
\dot{\lambda}_{d r} \\
\dot{\lambda}_{q r}
\end{array}\right]=\left[\begin{array}{cc}
\frac{-1}{T_{r}} & -\omega_{r} \\
\omega_{r} & \frac{-1}{T_{r}}
\end{array}\right]\left[\begin{array}{l}
\lambda_{d r} \\
\lambda_{q r}
\end{array}\right]+\frac{L_{m}}{T_{r}}\left[\begin{array}{c}
i_{d r} \\
i_{q r}
\end{array}\right]
$$

The above equations give the rotor fluxes as functions of stator currents and rotor speed. Thus, if speed and stator current signals are known, the rotor fluxes may be estimated and then the corresponding unit vector signals can also be estimated. These equations are defined as the current model for flux estimation or adaptive model. The estimator that does not involve the quantity to be estimated (the rotor speed $\omega_{r}$ ) is considered as the reference model and the other estimator, which considers the rotor speed is regarded as the adjustable model. If parameters and rotor speed values are known, then the outputs of both reference and adjustable models should match. An adaptation algorithm with PI control as shown in Fig. 1, can be used to tune the speed so that the error $\xi=0$.

In designing the MRAS adaptation algorithm, it is important to take account of the system overall stability and to ensure that the estimated speed will converge to the desired value with satisfactory dynamic characteristics. Using Popov criteria for hyperstability for a globally asymptotically stable system, we can derive the following speed estimation relation [13]

$$
\hat{\omega}_{r}=\xi\left(K_{p}+\frac{K_{I}}{S}\right)
$$

where $\xi=X-Y=\hat{\lambda}_{d r} \lambda_{q r}-\lambda_{d r} \hat{\lambda}_{q r}$

The speed estimated from MRAS control is fed back to a speed controller and is compared against the reference speed to get the commanded output.

\section{THE LUENBERGER OBSERVER}

The Luenberger observer is an improved speed estimation method that operates on a closed-loop speed adaptive flux observer principle [14]. Although an estimator can be implemented both in open-loop and closed-loop forms, the main disadvantage of open-loop estimators is the effect the parameter deviations at low speeds on the drive performance in both steady-state and transient-state. The Luenberger observer shown in this paper is a deterministic observer, which is applicable to a linear, time-invariant deterministic system. The Luenberger observer is constructed by adding an error compensator to the induction motor in the stationary reference frame. Many of the today existing systems can be modeled by a state space description as

$$
\frac{d X}{d t}=A X+B V_{s}
$$

Where: $X=\left[\begin{array}{llll}i_{d s} & i_{q s} & \lambda_{d r} & \lambda_{q r}\end{array}\right]^{T} ; V_{s}=\left[\begin{array}{llll}v_{d s} & v_{q s} & 0 & 0\end{array}\right]^{T}$

Figure 2 show the block diagram of speed adaptive flux observer using the above motor model where the input voltage signals $v_{d s}$ and $v_{q s}$ are measured from the motor terminals. If the speed $\omega_{r}$ in parameter matrix A is known, the fluxes and currents can be derived from the (17). However, if the $\omega_{r}$ is not correct, there will be a deviation between the estimated and the actual states. In Fig. 2, the estimated currents are compared to the actual machine terminal currents, and the errors inject the auxiliary corrective signals $e G$ through the observer gain matrix $G$, so that matrix $e$ tends to vanish. The observer equation can be given as

$$
\frac{d \hat{X}}{d t}=\hat{A} \hat{X}+B V_{s}+G\left(\hat{i}_{s}-i_{s}\right)
$$

where $\hat{i}_{s}=\left[\begin{array}{ll}i_{d s} & i_{q s}\end{array}\right]$.

The observer also gives an estimation of the flux vector, as shown in Fig. 2. The speed adaptive flux observer allows the estimation of the unknown speed $\omega_{r}$. To derive the speed adaptation algorithm, Lyapunov theorem is used. In general, the estimation error of the stator currents and rotor fluxes is described by

$$
\frac{d e}{d t}=(A+G C) e-\Delta A \hat{X}
$$

where $e=X-\hat{X}$

$$
\begin{aligned}
& \Delta A=\hat{A}-A=\left[\begin{array}{cc}
0 & -\frac{\Delta \omega_{r} j}{c} \\
0 & \Delta \omega_{r} j
\end{array}\right] ; j=\left[\begin{array}{cc}
0 & -1 \\
1 & 0
\end{array}\right] \\
& \Delta \omega_{r}=\hat{\omega}_{r}-\omega_{r} ; c=\frac{\sigma L_{s} L_{r}}{L_{m}}
\end{aligned}
$$

Let us define the following Lyapunov candidate function.

$V=e^{T} e+\frac{\left(\hat{\omega}_{r}-\omega_{r}\right)^{2}}{\gamma}$

where $\gamma$ is a positive constant. Then, $\mathrm{d} V / \mathrm{d} t$ becomes



Fig. 2. Luenberger speed adaptive flux observer. 
Proceedings of the 2008 International Conference on Electrical Machines

where $e_{i d s}=i_{d s}-\hat{i}_{d s}$ and $e_{i q s}=i_{q s}-\hat{i}_{q s}$

From the above equation, we can derive the following speed estimation adaptation scheme

$\frac{d \hat{\omega}_{r}}{d t}=\frac{\lambda\left(e_{i d s} \hat{\lambda}_{q r}-e_{i q s} \hat{\lambda}_{d r}\right)}{c}$

If the observer gain matrix $G$ is chosen such that the first term of (21) is negative-semi definite, the speed adaptive flux observer is stable. Since the speed $\omega_{r}$ can change quickly, the following proportional and integral adaptive scheme is used in the speed adaptation algorithm to improve the speed estimation response

$\hat{\omega}_{r}=K_{P}\left(e_{i d s} \hat{\lambda}_{q r}-e_{i q s} \hat{\lambda}_{d r}\right)+K_{I} \int\left(e_{i d s} \hat{\lambda}_{q r}-e_{i q s} \hat{\lambda}_{d r}\right) d t$

where $K_{P}$ and $K_{I}$ are arbitrary positive gains.

Although the speed estimation accuracy is improved by the observer, there is a finite parameter variation (particularly in the stator and rotor resistances) effect. The estimation error tends to be more dominant as the speed approaches zero.

\section{THE KALMAN FILTER}

The Kalman filter, is a special class of linear observer (deterministic type), derived to meet a particular optimality stochastic condition. The Kalman filter provides an automatic design procedure thus relieving many of the design decision associated with the explicit design of the Luenberger observer [14]. The Kalman filter has two forms: basic and extended. The Extended Kalman filter (EKF) can be used for nonlinear systems. This means that the plant model is extended by extra variables, in our case by mechanical speed. The Kalman filter allows obtaining no measured state variables (rotor speed $\omega_{r}$, components of rotor flux vector $\lambda_{d r}, \lambda_{q r}$ ) with usage measured state variables (components of stator current space vector $i_{d s}$, $i_{q s}$ ) and as well noise and measurements statistics [15].

A new state vector containing the original states and the parameter to be estimated is then set

$\left[\begin{array}{lllll}i_{d s} & i_{q s} & \lambda_{d r} & \lambda_{q r} & \omega_{r}\end{array}\right]$

Since KF is a stochastic filter, the discrete nonlinear stochastic model of the motor must be used. This is obtained from the model given in [6] and has the following form.

$$
\left\{\begin{array}{l}
X(k+1)=f(X(k), U(k), k)+W(k) \\
Y(k)=h(X(k), k)+V(k)
\end{array}\right.
$$

where $Y(k)$ is a vector containing the $d-q$ components of the stator current space vector, $U(k)$ is a vector of excitation signals, which are the $d-q$ components of the stator voltage space vector, $X(k)$ is a vector containing the states, $W(k)$ and $V(k)$ are respectively the process and the measurement noise vectors at time $k$.
$\begin{cases}E\{W(k)\}=0, & E\left\{W(k) W(j)^{T}\right\}=Q \delta_{k j}, Q \geq 0 \\ E\{V(k)\}=0, & E\left\{V(k) V(j)^{T}\right\}=R \delta_{k j}, \quad R \geq 0\end{cases}$

where $Q$ and $R$ are respectively the process and the measurement covariance matrices.

The Extended Kalman Filter equations are [6]

$$
\left\{\begin{aligned}
& K(k)=F(k) P(k) H^{T}\left[H P(k) H^{T}+R\right]^{-1} \\
& \hat{X}(k+1)= f(\hat{X}(k), U(k))+K(k)[Y(k)-H \hat{X}(k)] \\
& P(k+1)= F(k) P(k) F^{T}(k)+Q \\
&-K(k)\left[H P(k) H^{T}+R\right] K^{T}(k)
\end{aligned}\right.
$$

where $\hat{X}(k)$ is the state estimate, $P(k)$ is the estimation error covariance matrix, $K(k)$ is the Kalman gain matrix, $F(k)$ and $H$ are given by:

$$
\left\{\begin{array}{l}
F(k)=\left.\frac{\partial}{\partial X}\{f(X(k), U(k), k)\}\right|_{\hat{X}(k), U(k)} \\
H=\left.\frac{\partial}{\partial X}\{h(X(k), k)\}\right|_{\hat{X}(k), U(k)}
\end{array}\right.
$$

The Kalman filter concept is then illustrated by Fig. 3 .

\section{SimULATIONS RESUlts}

The above presented three speed sensorless control techniques have been applied on a $37-\mathrm{kW}$ induction motor drive propelling an electric vehicle whose ratings are given in the appendix. These techniques, namely MRAS, Luenberger observer and Kalman filter, have been compared in terms of influence on the drive performance and implementation complexity. The comparisons are based on the steady-state error and the vehicle speed and torque response dynamics.

Numerical simulations have been carried out using the urban ECE-15 cycle (Fig. 4) [9].

In all the three control systems, the main control inputs were torque and flux references. Operating conditions and sensing variables are considered to be ideal for all the three systems and the same tests were simulated.

The induction motor torque, flux, and speed for speed sensor-based MRAS control and two sensorless control methods (Luenberger and Kalman Filter observers) are shown in Figs. 5 to 7.

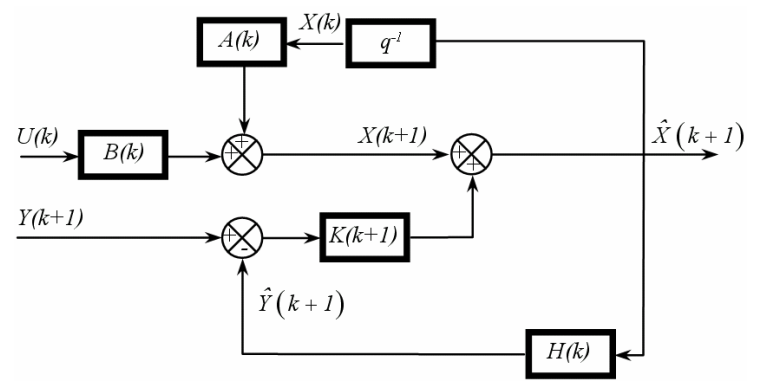

Fig. 3. Kalman filter block diagram. 
These simulation results show that during start-up, the MRAS control method reaches the required flux and torque significantly faster than sensorless methods. In speed sensor MRAS control, the required torque is not reached until the rated flux is reached. This is due to the fact that MRAS control uses the motor currents as control variables and maintains the motor within its current ratings at all times. Because of the PI controller in the speed estimation loop, there is a steady-state error in the motor speed. This error depends on the reference values as well as on the motor speed. Kalman filter system has steady-state error under no-load and load conditions but for MRAS and Luenberger observer have no steady-state error for both high- and low-speed and for any load condition. Moreover, it can be observed that the torque ripple for speed sensorless methods is higher than speed sensor-based MRAS control when the same sampling period is used for both schemes. The Kalman filter observer method has a greater speed variation compared to the Luenberger and MRAS control. The Luenberger scheme also has slight speed variations when compared to MRAS control.

The implementation of all three control methods is almost similar except for the additional speed estimation blocks in the MRAS and in the Luenberger method. One can examine the complexity of the three schemes in a general manner in order to predict the implementation issues. For MRAS, the problem of choosing the coefficients of the adaptation mechanism as well as loop stability is not straightforward. For the Luenberger observer, the only critical problem may be the adaptation of the gain matrix so that the poles of the estimator are in the unit circle. The MRAS and Luenberger observer does not seem to be affected by noise, while Kalman filter is particularly noise-sensitive.

\section{CONCLUSIONS}

This paper dealt with a comparative study of speed sensorless control techniques, namely MRAS, Luenberger observer and Kalman filter, for an induction motor drive propelling an electric vehicle. Simulations have been carried out on a $37-\mathrm{kW}$ induction motor drive based EV. These simulations have taken into account the vehicle aerodynamics.

The advantages of automotive speed sensorless drives are increased reliability (no possibility of tachometer failure), lower cost, reduced size of the drive system, and elimination of sensor cables. However, there are some limitations to speed estimation methods for sensorless control.



Fig. 4. European ECE-15 driving cycle.
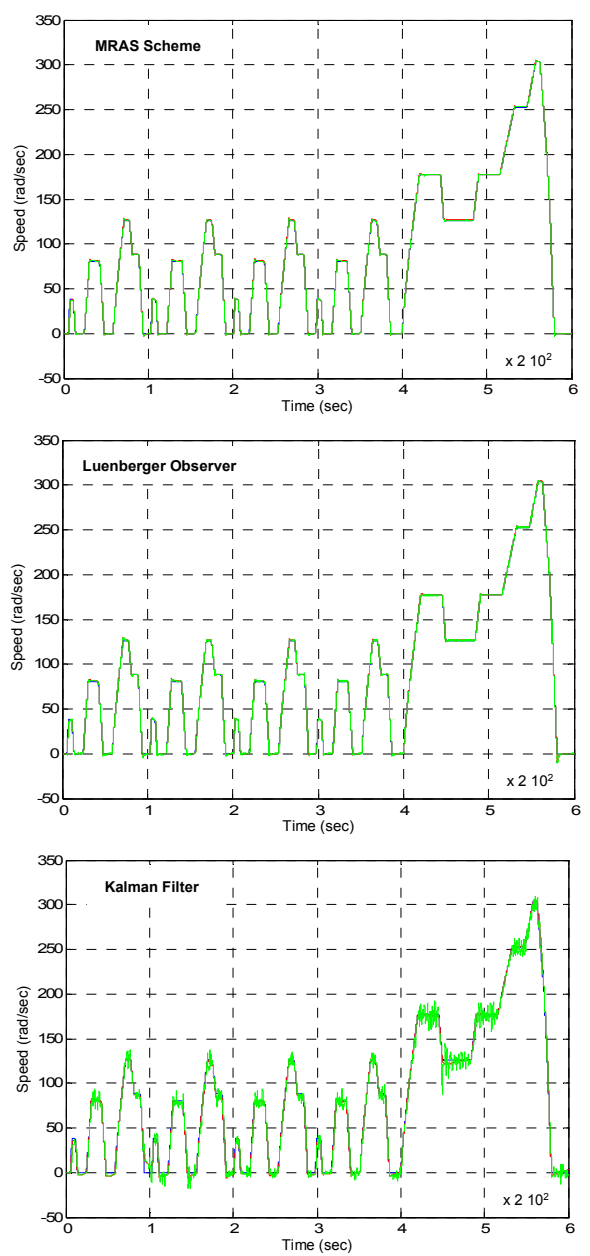

Fig. 5. Estimated, measured and reference vehicle speed.

Speed estimation methods experience problems at low speeds, which are responsible for poor drive performance in that speed range. At low speeds, the accuracy deteriorates due to parameter variation. There is a finite parameter variation especially in stator and rotor resistances although the speed estimation accuracy is improved by the Luenberger observer and the Kalman filter. As the speed approaches zero the error tends to be more dominant. Because of the pure integration of the voltage signals, the MRAS model is difficult to implement, particularly at low speeds. Instead of integration, if the corresponding signals are compared through a low-pass filter the MRAS speed estimation algorithm still remains valid and shows much better performance.

\author{
APPENDIX \\ RATED DATA OF THE SimUlated INDUCTION MOTOR \\ $37 \mathrm{~kW}, 50 \mathrm{~Hz}, 400 / 230 \mathrm{~V}, 64 / 111 \mathrm{~A}, 24.17 \mathrm{Nm}, 2960 \mathrm{rpm}$ \\ $R_{s}=85.1 \mathrm{~m} \Omega, R_{r}=65.8 \mathrm{~m} \Omega, L_{s}=31.4 \mathrm{mH}, L_{r}=29.1 \mathrm{mH}, L_{m}=29.1 \mathrm{mH}$ \\ $J=0.23 \mathrm{~kg} \cdot \mathrm{m}^{2}$ \\ EV Mechanical and Aerodynamic Parameters \\ $m=1540 \mathrm{~kg}$ (two $70 \mathrm{~kg}$ passengers), $A=1.8 \mathrm{~m}^{2}, r=0.3 \mathrm{~m}$ \\ $\mu_{r r 1}=0.0055, \mu_{r r 2}=0.056, C_{a d}=0.19, G=104, \eta_{g}=0.95$ \\ $T=57.2 \mathrm{Nm}$ (stall torque), $v_{0}=4.155 \mathrm{~m} / \mathrm{sec}, g=9.81 \mathrm{~m} / \mathrm{sec}^{2}, \rho=0.23 \mathrm{~kg} / \mathrm{m}^{3}$
}


Proceedings of the 2008 International Conference on Electrical Machines


Fig. 6. The Electric vehicle induction motor torque.

\section{REFERENCES}

[1] J. Holtz, "Sensorless control of induction machines-With or without signal injection?," IEEE Trans. Industrial Electronics, vol. 53, n ${ }^{\circ}$, pp. $7-$ 30, February 2006.

[2] L. Harnefors et al., "Complete stability of reduced-order and full-order observers for sensorless IM drives," IEEE Trans. Industrial Electronics, vol. 55, n³, pp. 1319-1329, March 2008.

[3] C. Lascu et al., "Comparative study of adaptive and inherently sensorless observers for variable-speed induction-motor drives," IEEE Trans. Industrial Electronics, vol. 53, $\mathrm{n}^{\circ}$ 1, pp. 57-65, February 2006.

[4] S. Bolognani et al., "Parameter sensitivity analysis of an improved openloop speed estimate for induction motor drives," IEEE Trans. Power Electronics, vol. 23, n4, pp. 2127-2135, July 2008.

[5] K.B. Lee et al., "Reduced-order extended Luenberger observer based sensorless vector control driven by matrix converter with nonlinearity compensation, IEEE Trans. Industrial Electronics," vol. 53, n 1, pp. 6675, February 2006.

[6] M. Barut et al., "Experimental evaluation of braided EKF for sensorless control of induction motors," IEEE Trans. Industrial Electronics, vol. 55, n², pp. 620-632, February 2008.

[7] M. Depenbrock et al., "Model-based speed identification for induction Machines in the whole operating range," IEEE Trans. Industrial Electronics, vol. 53, n¹, pp. 31-40, February 2006.
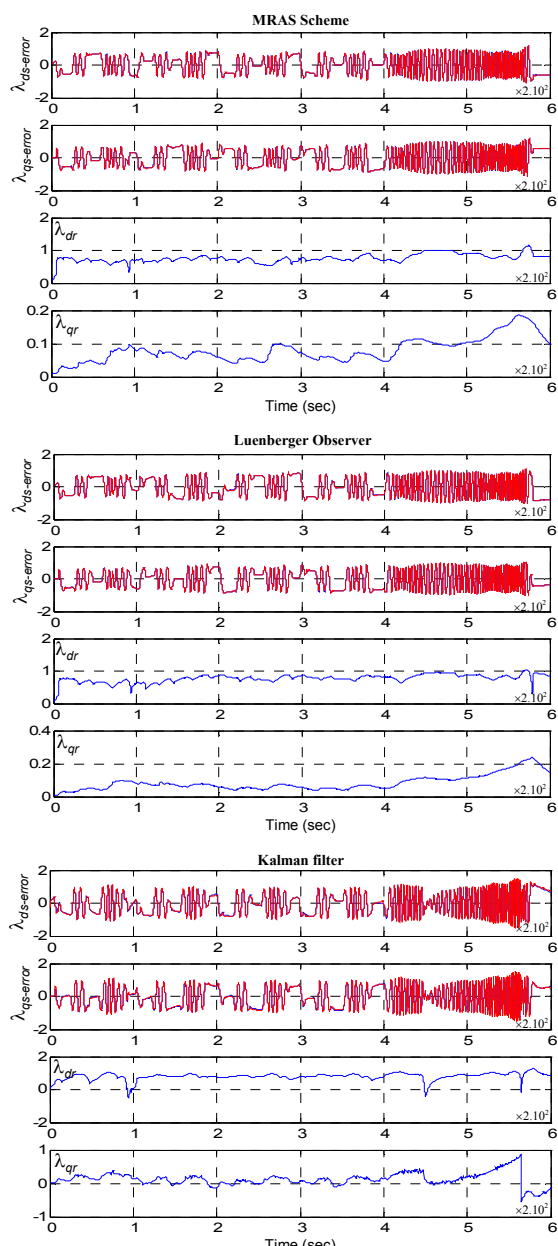

Fig. 7. The Electric vehicle induction motor stator and rotor fluxes.

[8] M. Hasegawa, "Robust-adaptive-observer design based on $\gamma$-positive real problem for sensorless induction-motor drives," IEEE Trans. Industrial Electronics, vol. 53, n ${ }^{\circ} 1$, pp. 76-85, February 2006.

[9] A. Haddoun et al., "Modeling, analysis, and neural network control of an EV electrical differential," IEEE Trans. Industrial Electronics, vol. 55, n6, pp. 2286-2294, June 2008.

[10] A. Haddoun et al., "A loss-minimization DTC scheme for EV induction motors," IEEE Trans. Vehicular Technology, vol. 56, n 1 , pp. 81-88, January 2007.

[11] R. Pena et al., "Sensorless control of doubly-fed induction generators using a rotor-current-based MRAS observer," IEEE Trans. Industrial Electronics, vol. 55, ${ }^{\circ} 1$, pp. 330-339, January 2008.

[12] K. Ohyama et al., "Comparative analysis of experimental performance and stability of sensorless induction motor drives," IEEE Trans. Industrial Electronics, vol. 53, nㅅ․ pp. 178-186, February 2006.

[13] M. Tomita et al., "New sensorless control for brushless DC motors using disturbance observers and adaptive velocity estimations," IEEE Trans. Industrial Electronics, vol. 45, n², pp. 274-282, April 1998.

[14] T.S. Kwon et al., "Speed sensorless stator flux-oriented control of induction motor in the field weakening region using Luenberger observer," IEEE Trans. Power Electronics, vol. 20, n²4, pp. 864-869, July 2005.

[15] L. Harnefors, "Instability phenomena and remedies in sensorless indirect field oriented control," IEEE Trans. Power Electronics, vol. 15, n, pp. 733-743, July 2002. 